\title{
THE APPLICATION OF MATHEMATICAL MODEL OF DEFORMATION PROCESS OF THE PLATE OF FINITE THICKNESS FOR RESEARCH OF STRESS-STRAIN STATE OF ICE COVER
}

\author{
O. Marchenko ${ }^{1}$, A. Sergeeva ${ }^{2}$, V. Odinokov ${ }^{3}$ \\ DOI: http://doi.org/10.15350/L_26/8/18
}

\begin{abstract}
In this paper we have researched the stress-strain condition of ice cover, which is in contact the ice-breaking device with specific geometry and with given speed of movement. These studies were conducted by using of a mathematical model of the process of deformation of the plate of finite thickness and under system of loads.
\end{abstract}

Keywords: mathematical model, deformation, stress-strain condition, ice cover.

Разработка экологически безопасных способов и устройств для прокладывания судоходных каналов, продление навигации на внутренних водных путях является важной и широкомасштабной задачей. Обеспечить передвижение судов в условиях ледяного покрова необходимо для расширения освоения северных регионов, их ресурсов. Проблема заключается не только в разрушении ледяного покрова, но и в обеспечении максимально безопасного продвижения водного транспорта, что подтверждается патентами, направленными на разработку способов разрушения ледяного покрова. С разрушением льда связано немало экспериментальных исследований $[1,2]$.

В данной работе рассматривается ледяной покров рек и его разрушение путем внедрения в лед катамарана, выполненного в виде ледокольной приставки. Ледяной покров рек неоднороден. Особенности его строения зависят от условий льдообразования [3]. Ледяной покров, состоящий из смерзшихся кусков битого льда и шуги, формируется благодаря осенним ледоходам, большому количеству поверхностных ледяных образований и шуги. Весной такой лед разрушается медленнее льда, формирующегося в стабильных гидрометеорологических условиях, который имеет большую плотность, но сравнительно легко разделяется на кристаллы и

10lesya Marchenko, postgraduate student of FSBIS Institute of machinery and metallurgy of Far Eastern Branch of Russian Academy of Sciences, Russia.

${ }^{2}$ Anastasia Sergeeva, Candidate of Physical and Mathematical Sciences, Deputy Director of Science of FSBIS Institute of machinery and metallurgy of Far Eastern Branch of Russian Academy of Science, Russia.

3Valeriy Odinokov, Doctor of Engineering Sciences, Chief Researcher of FSBIS Institute of machinery and metallurgy of Far Eastern Branch of Russian Academy of Science, Russia. 
их группы.

Для проведения анализа напряженно-деформированного состояния льда примем исследуемый ледяной покров однородным и изотропным. Исследование влияние системы нагрузок на лед в виде ледокольной приставки [4] будем исследовать с применением математической модели пластины конечной толщины, находящейся под действием системы нагрузок, приведенной в работе [5]. Расчеты проводились с применением программного продукта [6]. На рис. 1 представлена схема ледокольной приставки.

a)

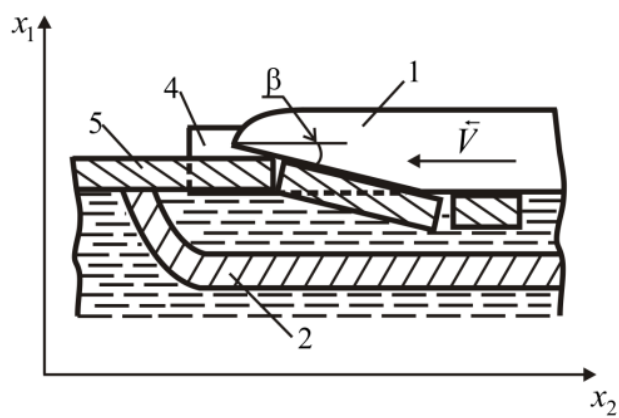

б)

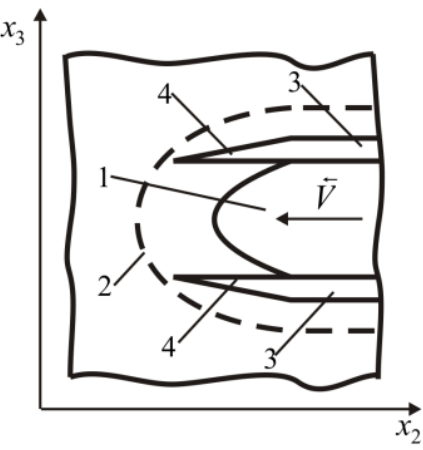

Рис. 1. Схема ледоразрушающего устройства: а - сечение плоскостью симметрии проходящей вдоль судна; б - вид сверху носовой части судна

Предполагается, что ледокольное судно начинает двигаться на чистой воде с заданной скоростью, постепенно приближаясь к кромке припая - неподвижного льда. Первой со льдом начинает контактировать подводная часть судна, заходя под ледяной покров. Загнутый нос подводной части 2 судна 1 скользит по нижней поверхности льда контактирующей с водой. В данном случае предполагается, что поверхность льда, касающаяся воды гладкая, твердая, не способствует смерзанию составляющих судна со льдом и не создает препятствий для продвижения судна с постоянной заданной скоростью, равной 5 км/час.

Расстояние между надводной и подводной частями судна регулируемо и устанавливается в зависимости от толщины льда до начала движения судна при помощи гидроцилиндров и воздушных секций подводной части ледоразрушающего устройства. После захода подводной части судна под лед и дальнейшем его продвижении боковые клинья 4 врезаются в лед, создавая дополнительную нагрузку на ледяной покров. Продолжая движение ледокольное судно, носовой отсек надводной части которого находится под углом $\beta$ относительно припая, наползает на бесснежный лед 5 и подминает его под себя. Обломки льда продвигаются между надводной и подводной частями устройства при помощи системы фрез, установленных по всей нижней части надводной составляющей ледоразрушающего устройства. Таким образом, устройство обеспечивает себе безопасное продвижение в ледяном поле и создает судоходный канал для прохождения 
судов следующих за ним.

Геометрические параметры устройства и исследуемой области деформирования льда указаны на рис. 2 а,б толщина льда принимается равной 0,5 м.
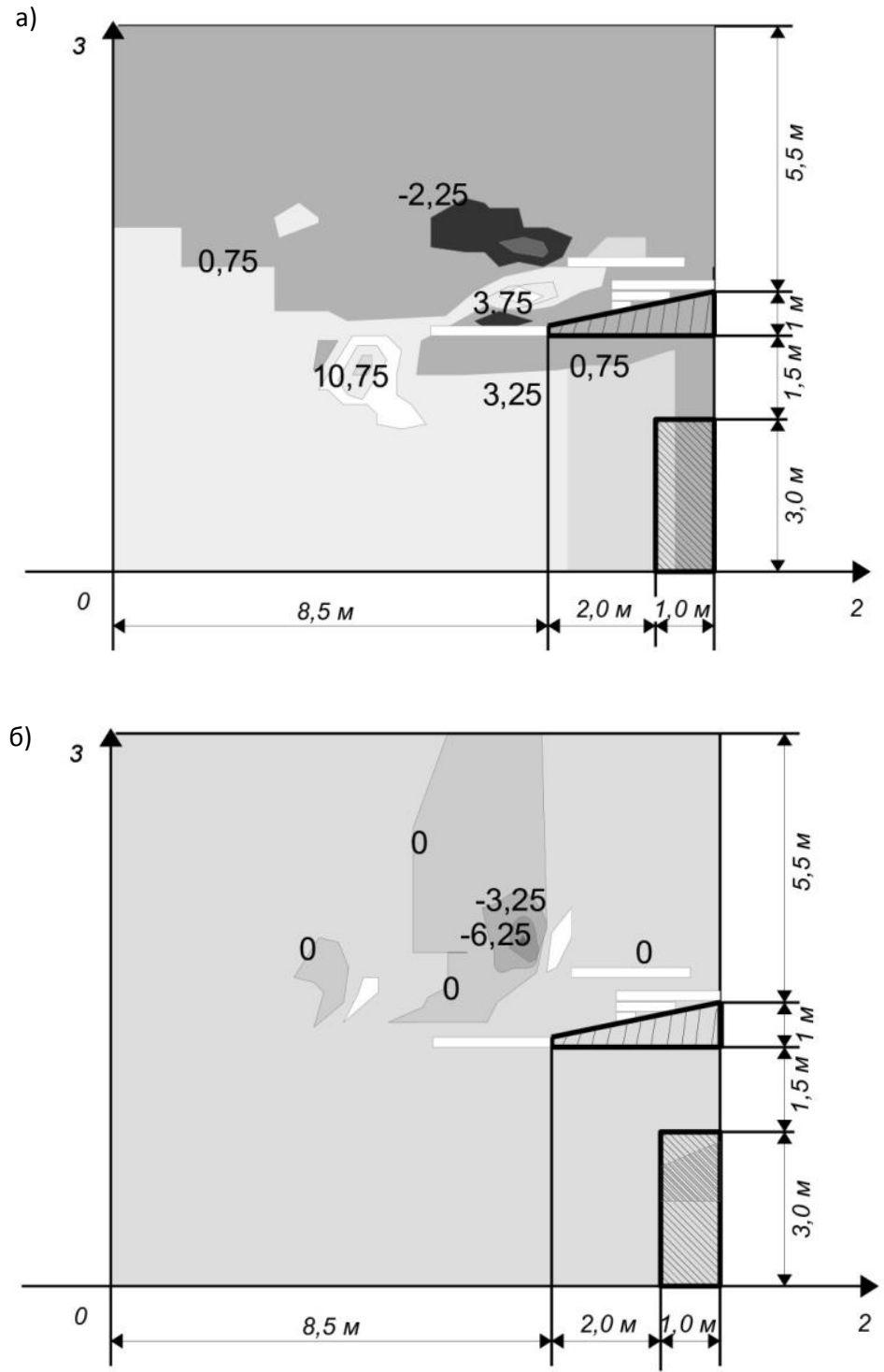

Рис. 2. Распределение напряжений в верхнем слое ледяного покрова, при контакте с ледокольной приставкой: а) - б22 МПа, б) - бз3 МПа

До образования магистральной трещины и других разрушений в ледяном покрове происходит рост напряженного состояния льда. Наибольшие напряжения находятся фронтально от клина над подводной частью. 
Нормальные напряжения, перпендикулярные действию устройства, носят растягивающий характер, наибольшие из них расположены у наклонной части клина. Напряженное состояние льда при удалении от устройства сглаживается. Как видно из рис. 2а напряжения, порождают развитие магистральной трещины, представленной на рис. 2 а,б в виде белой полосы. Фронтально от клина проходит основная трещина - магистральная, она разделит лед на две зоны - внутреннюю и внешнюю. У наклонной боковой поверхности клина возникают вторичные трещины, как показано на рис.2 в этой области во льду возникнут трещины, разделяющие его на мелкие фрагменты.

После образования магистральной трещины и вторичных трещин общее напряженное состояние льда ослабится, на рис. 2 указаны значения напряжений в установившемся состоянии. На данном этапе деформирования в ледяном покрове возникнет изгибающий момент, который приведет к нарушению сплошности льда на периферии.

Анализируя полученные результаты можно сделать вывод о том, что применение данного устройства эффективно для разрушения ледяного покрова толщиной 0,5 м.

\section{References:}

[1] Лосет С., Шхинек К., Гудместад О., Хойланд К. Воздействие льда на морские и береговые сооружения. СПб.: Издательство «Лань», 2010. 272 с.

[2] Богородский В. В., Гаврило В. П., Недошивин О. А. Разрушение льда. Методы, технические средства. Л.: Гидрометеоиздат, 1983.

[3] Богородский В. В., Гаврило В. П. Физические свойства. Современные методы гляциологии. Л.: Гидрометеоиздат, 1980.

[4] Пат. 2276037 РФ МПК В 63 В 35/08. Ледокольное судно / В.И. Одиноков, В.Л. Колмогоров. № 2004114052/11; Заяв. 06.05.2004; Опубл. 10.05.2006, Бюл. № 13.

[5] Сергеева А.М., Одиноков В.И, Марченко О.В. Математическое моделирование процессов деформирования пластины конечной толщины, находящейся под действием системы нагрузок// Приоритеты и научное обеспечение технологического прогресса: сборник статей международной научно-практической конференции (10 октября 2016г., г.Нижний Новгород). Уфа: Аэтерна, 2016. С100102.

[6] Одиноков В.И., Сергеева А.М., Захарова Е.А. Моделирование процесса разрушения ледяного покрова с помощью ледокольной приставки. Свидетельство об официальной регистрации программы для ЭВМ № 2007614584. Зарегистриро-

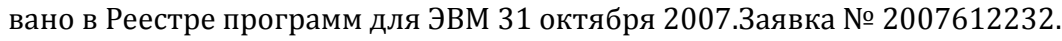

